\title{
Synergetic Exploitation of the Sentinel-2 Missions for Validating the Sentinel-3 Ocean and Land Colour Instrument (OLCI) Terrestrial Chlorophyll Index (OTCI) over a Vineyard Dominated Mediterranean Environment
}

\author{
Luke A. Brown, Jadunandan Dash, Antonio L. Lidón, Ernesto Lopez-Baeza, and Steffen Dransfeld
}

\begin{abstract}
Continuity to the Medium Resolution Imaging Spectrometer (MERIS) Terrestrial Chlorophyll Index (MTCI) will be provided by the Ocean and Land Colour Instrument (OLCI) on-board the Sentinel-3 missions. To ensure its utility in a wide range of operational applications, validation efforts are required. In the past, direct validation has been constrained by the need for costly airborne hyperspectral data acquisition, due to the lack of freely available high spatial resolution imagery incorporating appropriate spectral bands. The Multispectral Instrument (MSI) on-board the Sentinel-2 missions now offers a promising alternative. We explored the synergetic use of MSI data for validation of the OLCI Terrestrial Chlorophyll Index (OTCI) over the Valencia Anchor Station, a large agricultural site in the Valencian Community, Spain. Using empirical and machine learning techniques applied to MSI data, in-situ measurements were upscaled to the moderate spatial resolution of the OTCI. An $\mathrm{RMSE}_{\mathrm{CV}}$ of $0.09 \mathrm{~g} \mathrm{~m}^{-2}\left(\mathrm{NRMSE}_{\mathrm{CV}}=20.93 \%\right)$ was achieved, highlighting the valuable information MSI data can provide when used in synergy with OLCI data for land product validation. Good agreement between the OTCI and upscaled in-situ measurements was observed $(r=0.77, p<0.01)$, providing increased confidence to users of the product over vineyard dominated Mediterranean environments.
\end{abstract}

Index Terms-Vegetation biophysical variables, canopy chlorophyll content, Sentinel-2, Sentinel-3, validation

\section{INTRODUCTION}

A $\mathrm{S}$ the key photosynthetic pigment in plants, the amount of chlorophyll plays an important role in determining vegetation physiological status. Therefore, canopy chlorophyll content (CCC) is a sensitive indicator of plant health and a key input to models of carbon exchange, and, in turn, terrestrial productivity. In the visible region of the electromagnetic

This work was supported in part by the European Space Agency and European Commission through the Sentinel-3 Mission Performance Centre.

L. A. Brown and J. Dash are with the School of Geography and Environmental Science at the University of Southampton, Highfield, Southampton, SO17 1BJ, United Kingdom (e-mail: 1.a.brown@soton.ac.uk).

A. L. Lidón is with the Research Institute for Water and Environmental Engineering at the Technical University of Valencia, Camino de Vera, 46022 Valencia, Spain. spectrum, the presence of chlorophyll in leaves causes strong absorption, whereas in the near-infrared, strong reflection occurs due to scattering within the internal structure of the leaf. The transition between these two zones (i.e. the point of maximum slope) is known as the red-edge, and is a unique feature of the vegetation reflectance spectrum. As CCC increases, the absorption feature broadens, shifting the red-edge towards longer wavelengths. Thus, the position of the red-edge is strongly related to CCC [1], and has been used to estimate CCC from various different sources of remote sensing data [2], [3].

Traditional methods to estimate the position of the red-edge were designed for use with continuous spectra as opposed to the discrete bands provided by the optical instruments on-board earth observation satellites [4], [5]. The Medium Resolution Imaging Spectrometer (MERIS) on-board ENVISAT was the first operational satellite instrument to collect data in the rededge region. The MERIS Terrestrial Chlorophyll Index (MTCI) was developed to utilize this red-edge spectral information and provide the first global surrogate of CCC at a spatial resolution of $300 \mathrm{~m}$ [6]. Unlike other spectral vegetation indices, which suffer from asymptotic saturation, the MTCI remains sensitive to high CCC. Since its release as a standard MERIS level 2 (L2) land product, the MTCI has been used in a wide range of applications, including land surface phenology monitoring [7]-[9], land cover mapping [10], [11], vegetation status assessment [12], terrestrial primary productivity estimation [13]-[15], and crop yield prediction [16].

As one of the L2 land products from the Ocean and Land Colour Instrument (OLCI) on-board Sentinel-3, the OLCI Terrestrial Chlorophyll Index (OTCI) is designed to provide continuity to the MTCI. The OTCI is calculated as

E. Lopez-Baeza is with the Department of Earth Physics and Thermodynamics at the University of Valencia, Calle Dr. Moliner, 50, 46100 Burjassot, Spain.

S. Dransfeld is with the European Space Research Institute at the European Space Agency, Largo Galileo Galilei 1, 00044 Frascati (Roma), Italy. 
$O T C I=\frac{R_{\text {band } 12}-R_{\text {band } 11}}{R_{\text {band } 11}-R_{\text {band } 10}}$

where $R_{\text {band 12 }}, R_{\text {band 11 }}$, and $R_{\text {band } 10}$ are the reflectance values (corrected for gaseous absorption and Rayleigh scattering) in OLCI bands centered at $753.75 \mathrm{~nm}, 708.75 \mathrm{~nm}$, and $681.25 \mathrm{~nm}$ respectively.

To ensure the utility of the OTCI in a wide range of operational applications, validation efforts are required to quantify its accuracy and uncertainty. The moderate spatial resolution of the product and the heterogeneity of the terrestrial landscape represent a challenge to direct validation, as in-situ measurements of biophysical variables are typically pointbased. To overcome this challenge, the 'two-stage' or 'bottomup' approach was proposed by the Land Product Validation (LPV) sub-group of the Committee on Earth Observation Satellites (CEOS) Working Group on Calibration and Validation (WGCV) [17]. In this approach, individual in-situ measurements are performed within elementary sampling units (ESUs) that approximate the extent of a pixel of high spatial resolution imagery, which is used in upscaling. By relating the spectral information in the high spatial resolution imagery with the in-situ measurements, a high spatial resolution map of the biophysical variable of interest can be produced. This high spatial resolution map can then be aggregated to the moderate spatial resolution of the product in question to facilitate comparison.

Prior to the launch of the Sentinel-2 missions, application of the 'two-stage' or 'bottom-up' approach for the direct validation of moderate spatial resolution CCC products was constrained by a lack of freely available high spatial resolution imagery incorporating appropriate spectral bands. Validation efforts necessitated costly airborne hyperspectral acquisition, making them a relatively infrequent and logistically challenging activity. As a result, products such as the MTCI and OTCI have reached only the first stage of the CEOS WGCV LPV hierarchy, which states that product accuracy is assessed over a small set of locations and time periods [18]. With a spatial resolution of $20 \mathrm{~m}$ in multiple red-edge bands, the Multispectral Instrument (MSI) on-board the Sentinel-2 missions offers a promising alternative in this respect. As such, in this paper, we explore the synergetic use of MSI data for validation of the OTCI, and provide an initial performance assessment of the product over a vineyard dominated Mediterranean environment.

\section{MATERIALS AND METHODS}

\section{A. In-situ data collection}

An in-situ data collection campaign was carried out between $14^{\text {th }}$ and $18^{\text {th }}$ June 2017 , covering a $10 \mathrm{~km} \mathrm{x} 10 \mathrm{~km}$ area of the Valencia Anchor Station, a large agricultural site in the Valencia Community, Spain (Fig. 1). Located approximately $80 \mathrm{~km}$ west of Valencia in the Utiel-Requena Plateau, the site is dominated by vineyards, which account for approximately $75 \%$ of its land cover. Other important species include almond and olive, whilst smaller areas of shrubland and Aleppo pine forest are also present. Temperatures range from $-15^{\circ} \mathrm{C}$ in winter to $45^{\circ} \mathrm{C}$ in summer, with a mean annual temperature of $14^{\circ} \mathrm{C}$, whilst mean annual precipitation is approximately 450 $\mathrm{mm}$ [19]. In addition to its vineyard dominated Mediterranean environment, which has been poorly represented in previous validation efforts, the site was selected as a result of its flat topography, which minimizes terrain effects, good accessibility, which simplifies campaign logistics, and homogeneity at the moderate spatial resolution of the OTCI.

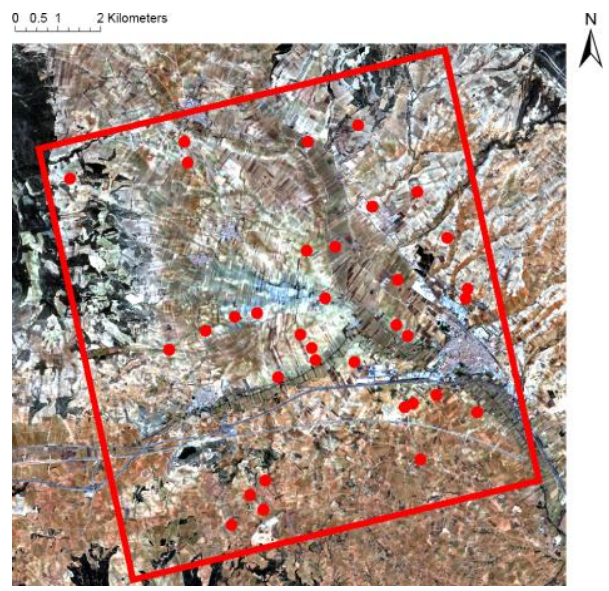

Fig. 1. Sentinel-2A MSI true colour composite of the Valencia Anchor Station acquired on $15^{\text {th }}$ June 2017 . The red box and circles indicate the 10 $\mathrm{km} \times 10 \mathrm{~km}$ area and ESUs over which in-situ data collection took place.

34 ESUs were established over the site, of which 29 corresponded to vineyards and 5 to almond/olive groves. The extent of each ESU was $40 \mathrm{~m}$ x $40 \mathrm{~m}$, to accommodate known positional uncertainties in the $20 \mathrm{~m}$ MSI data utilized for upscaling [20]. The central location of each ESU was determined using a Garmin eTrex 10 global positioning system (GPS) receiver, with an uncertainty of less than $10 \mathrm{~m}$. Within each ESU, measurements of leaf area index (LAI) were performed at 20 sampling locations (both within and between rows), whilst measurements of leaf chlorophyll concentration (LCC) were performed at 10 sampling locations (within rows only). Measurements were performed over transects positioned diagonally with respect to planting direction, enabling the row structure of the canopy to be characterized [21] (Fig. 2). The $\mathrm{CCC}$ of each ESU was determined as the product of LAI and LCC.

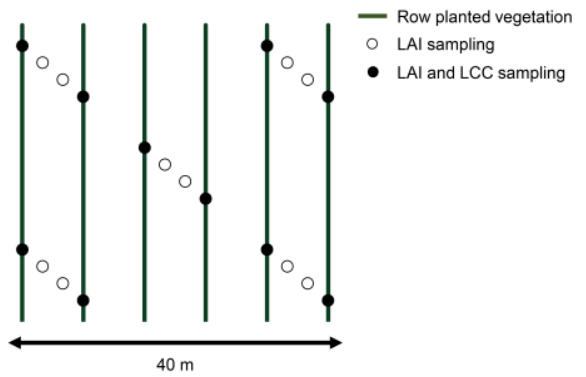

Fig. 2. Sampling locations within an ESU (not to scale).

LAI was determined using digital hemispherical photography (DHP), making use of a Nikon Coolpix 4500 equipped with an FC-E8 fisheye lens, which was calibrated according to the procedures of [22]. DHP data were classified and processed to yield estimates of LAI according to [23], 
accounting for the effects of foliage clumping using the method of [24]. Each image was divided into 6 zenith rings of $10^{\circ}$, and each ring was further divided into 36 azimuth cells of $10^{\circ}$. LAI was then calculated as

$$
L A I=2 \sum_{i=1}^{6}-\overline{\ln P\left(\theta_{i}\right)} \cos \theta_{i} \sin \theta_{i} \mathrm{~d} \theta_{i}
$$

where $P\left(\theta_{i}\right)$ is the gap fraction in ring $i$, and $\theta_{i}$ is its central zenith angle.

LCC was determined using a Konica Minolta SPAD-502 chlorophyll meter. By measuring leaf transmittance at $650 \mathrm{~nm}$ and $940 \mathrm{~nm}$, the instrument calculates a relative value that is proportional to LCC as

$$
M=k \log \frac{I_{0_{650}} I_{940}}{I_{650} I_{0940}}+C
$$

where $I_{650}, I_{940}, I_{0_{650}}$, and $I_{0940}$ are the incident and transmitted electromagnetic radiation at $650 \mathrm{~nm}$ and $940 \mathrm{~nm}$ respectively, whilst $k$ and $C$ are confidential slope and offset coefficients undisclosed by the manufacturer [25]. At each sampling location, 3 leaves were measured from the top, middle, and bottom of the canopy, enabling vertical variations in LCC to be characterized. 6 replicates were performed per leaf, yielding a total of 18 measurements per sampling location, and 180 measurements per ESU. Relative values were converted to absolute units using calibration functions specific to each vegetation type. For vineyards, a calibration function was derived from data collected at the Valencia Anchor Station in 2016, when SPAD-502 measurements were performed on 103 leaves whose LCC was then determined spectrophotometrically, following pigment extraction according to [26]. For almond/olive groves, the calibration function presented by [27] for fruit trees was adopted.

\section{B. Generation of a high spatial resolution CCC reference map}

Two approaches were investigated to generate a high spatial resolution CCC reference map from Sentinel-2A MSI L2A data acquired on $15^{\text {th }}$ June 2017. The first involved machine learning techniques, and consisted of training an artificial neural network (ANN) for the retrieval of CCC using radiative transfer model (RTM) simulations. Modelling radiation transfer in row-structured canopies is challenging due to their heavily clumped nature and the strong dependency of the reflectance signal on viewing and illumination geometry. Therefore, in the Crop Reflectance Operational Models for Agriculture (CROMA) project, the Markov Chain Canopy Reflectance Model (MCRM) was modified to provide an improved description of row-structured canopies, resulting in the so-called 'rowMCRM' model [28], [29]. We applied the same modifications to another widely used canopy RTM, Scattering by Arbitrarily Inclined Leaves (4SAIL) [30], [31]. By describing the canopy as a series of geometric objects filled with turbid media, the resulting hybrid RTM enabled the fractions of visible canopy, sunlit soil, and shaded soil to be accounted for, providing a more realistic representation of rowstructured canopies than simpler one-dimensional RTMs.

The modified version of 4SAIL was coupled with leaf reflectance and transmittance spectra simulated by Leaf Optical
Properties Spectra (PROSPECT-4) [32], [33], and a total of 50,000 simulations were carried out by randomly drawing input parameters from a series of predefined uniform and truncated Gaussian distributions (Table I). The soil background was selected randomly from 10 possible spectra chosen from a spectral library [34] to reflect the sandy loam soils of the region (Fig. 3). Simulated spectra were convolved with the MSI spectral response functions to represent reflectance values in each MSI band [35]. They were then contaminated with wavelength dependent and independent Gaussian white noise consisting of both additive (0.01) and multiplicative (2\%) components according to [36], such that

$$
\begin{gathered}
R_{\text {cont }}(\lambda)=R_{\text {sim }}(\lambda)\left[1+\varepsilon\left(0, \sigma_{\text {multi }}(\lambda)\right)+\right. \\
\left.\varepsilon\left(0, \sigma_{\text {multi }}(\text { all })\right)\right]+\varepsilon\left(0, \sigma_{\text {add }}(\lambda)\right)+\varepsilon\left(0, \sigma_{\text {add }}(\text { all })\right)
\end{gathered}
$$

where $R_{\text {cont }}(\lambda)$ and $R_{\text {sim }}(\lambda)$ are the contaminated and simulated reflectance values in the band centered at $\lambda, \varepsilon(0, \sigma)$ is a Gaussian distribution with a mean of 0 , whilst $\sigma_{\text {add }}(\lambda)$, $\sigma_{\text {multi }}(\lambda), \sigma_{\text {add }}($ all $)$, and $\sigma_{\text {multi }}($ all $)$ are the additive and multiplicative components of wavelength dependent and independent Gaussian white noise respectively.

\begin{tabular}{|c|c|c|c|c|}
\hline Parameter & $\begin{array}{l}\text { Value } \\
\text { range }\end{array}$ & Mean & $\begin{array}{l}\text { Standard } \\
\text { deviation }\end{array}$ & Reference \\
\hline Structural parameter $(\mathrm{N})$ & 1.62 & - & 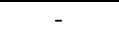 & [9], [10] \\
\hline $\begin{array}{l}\text { Chlorophyll a+b } \\
\left(\mu \mathrm{g} \mathrm{cm}^{-2}\right)\end{array}$ & $\begin{array}{c}27.4 \text { to } \\
43.7\end{array}$ & 34.2 & 3.6 & $\begin{array}{l}\text { This } \\
\text { study }\end{array}$ \\
\hline Water thickness $(\mathrm{cm})$ & 0.025 & - & - & [9], [10] \\
\hline Dry matter $\left(\mathrm{g} \mathrm{cm}^{-2}\right)$ & 0.0035 & - & - & {$[9],[10]$} \\
\hline Leaf area index & $\begin{array}{l}0.7 \text { to } \\
3.0\end{array}$ & 1.4 & 0.5 & $\begin{array}{l}\text { This } \\
\text { study }\end{array}$ \\
\hline Average leaf angle $\left({ }^{\circ}\right)$ & 45 & - & - & {$[9],[10]$} \\
\hline Hotspot parameter & 0.083 & - & - & [9], [10] \\
\hline Row height (m) & $\begin{array}{l}1.2 \text { to } \\
1.8\end{array}$ & - & - & $\begin{array}{l}\text { This } \\
\text { study }\end{array}$ \\
\hline Row width (m) & $\begin{array}{c}0.6 \text { to } \\
1.3\end{array}$ & - & - & $\begin{array}{l}\text { This } \\
\text { study }\end{array}$ \\
\hline Visible soil strip (m) & $\begin{array}{c}1.5 \text { to } \\
3.0\end{array}$ & 2.4 & 0.3 & $\begin{array}{l}\text { This } \\
\text { study }\end{array}$ \\
\hline $\begin{array}{l}\text { Difference between solar } \\
\text { azimuth angle and row } \\
\text { direction }\left({ }^{\circ}\right)\end{array}$ & $\begin{array}{l}0.3 \text { to } \\
125.7\end{array}$ & - & - & $\begin{array}{l}\text { This } \\
\text { study }\end{array}$ \\
\hline Observer zenith angle $\left(^{\circ}\right)$ & $\begin{array}{c}5.5 \text { to } \\
6.8\end{array}$ & - & - & $\begin{array}{l}\text { This } \\
\text { study }\end{array}$ \\
\hline Solar azimuth angle $\left(^{\circ}\right)$ & $\begin{array}{l}21.3 \text { to } \\
21.5\end{array}$ & - & - & $\begin{array}{l}\text { This } \\
\text { study }\end{array}$ \\
\hline $\begin{array}{l}\text { Relative azimuth angle } \\
\left({ }^{\circ}\right)\end{array}$ & $\begin{array}{c}18.9 \text { to } \\
44.1\end{array}$ & - & - & $\begin{array}{l}\text { This } \\
\text { study }\end{array}$ \\
\hline $\begin{array}{l}\text { Fraction of diffuse } \\
\text { radiation }\end{array}$ & 0.15 & - & - & $\begin{array}{l}\text { This } \\
\text { study }\end{array}$ \\
\hline
\end{tabular}

TABLE I

DISTRIBUTIONS FROM WHICH RTM INPUT PARAMETERS WERE RANDOMLY DRAWN

The ANN, which was comprised of a single hidden layer with 5 tangent sigmoid neurons, was trained using the LevenbergMarquardt minimization algorithm. Inputs consisted of the simulated bottom-of-atmosphere (BOA) reflectance values in MSI bands 3, 4, 5, 6, 7, 8a, 11 and 12, in addition to the cosine of the observer zenith angle, solar zenith angle and relative azimuth angle. $50 \%$ of simulations were used for training, and the remaining $50 \%$ were used for validation and testing. The validation set was used to prevent overfitting by early stopping (i.e. training of the ANN was halted when the error assessed 
using the validation set stopped decreasing). Once trained, the ANN was applied to the L2A MSI scene. Following [37], a bias correction based on the in-situ data was derived through ordinary least squares (OLS) regression analysis, and was then applied to the raw ANN retrievals.

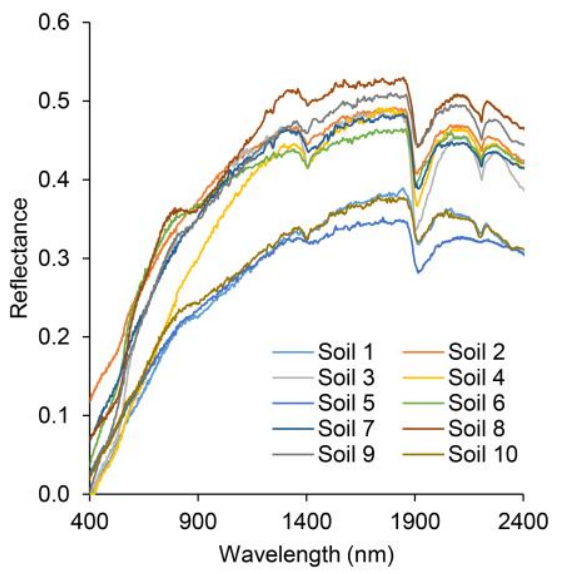

Fig. 3. Sandy loam soil spectra from which the soil background was randomly selected [34].

In the second approach, an empirical transfer function was established in order to generate a high spatial resolution CCC reference map from the MSI data. The transfer function was based on a modified version of the OTCI presented by [38], hereafter referred to as the Sentinel-2 Terrestrial Chlorophyll Index (S2TCI), which was calculated as

$S 2 T C I=\frac{R_{\text {band } 6}-R_{\text {band } 5}}{R_{\text {band } 5}-R_{\text {band } 4}}(5)$

where $R_{\text {band } 6}, R_{\text {band } 5}$, and $R_{\text {band } 4}$ are the BOA reflectance values in MSI bands centered at $740 \mathrm{~nm}, 705 \mathrm{~nm}$ and $665 \mathrm{~nm}$ respectively. The transfer function was derived using OLS regression analysis, enabling a relationship between the S2TCI and in-situ data to be established (using all in-situ observations).

For both retrieval approaches, agreement was assessed using the Pearson product-moment correlation coefficient, whilst retrieval accuracy was assessed in terms of the root mean square error (RMSE), calculated through leave-one-out cross validation as

$$
R M S E=\sqrt{\frac{\sum_{i=1}^{n}\left(p_{i}-o_{i}\right)^{2}}{n}}
$$

where $p_{i}$ is the predicted value, $o_{i}$ is the observed value, and $n$ is the number of observations. A normalized RMSE (NRMSE) was also calculated by dividing the RMSE by the mean of observed values.

\section{Aggregation of the high spatial resolution CCC reference map and validation of the OTCI}

Sentinel-3A OLCI L2 data were acquired on $18^{\text {th }}$ June 2017. To facilitate validation of the OTCI, areas of the $20 \mathrm{~m} \mathrm{CCC}$ reference map not covered by the considered land cover types (i.e. vineyards and almond/olive groves) were masked to avoid extrapolation. Masking was achieved using the environmental units classification presented by [19], which was derived from the Coordination of Information on the Environment (CORINE) land cover product. Once masked, the $20 \mathrm{~m} \mathrm{CCC}$ reference map was aggregated to the $300 \mathrm{~m}$ spatial resolution of the OTCI. Two aggregation approaches were investigated. The first involved mean value downsampling (the standard aggregation approach adopted in most current validation studies), whilst in the second, weighted mean value downsampling was carried out to better account for OLCI's point spread function (PSF). A grid of weights was generated based on an assumed two-dimensional Gaussian PSF, with a full width at half maximum (FWHM) of a single OLCI pixel (i.e. $300 \mathrm{~m}$ ) [39]. After aggregation, the two datasets were collocated. Once again, agreement was assessed using the Pearson product-moment correlation coefficient. An empirical relationship between the OTCI and CCC was established using OLS regression analysis, and the associated retrieval accuracy was again assessed using the RMSE and NRMSE, calculated through leave-one-out cross validation.

\section{RESULTS AND DISCUSSION}

\section{A. Accuracy of the $20 \mathrm{~m}$ CCC reference maps}

Of the two investigated approaches for the retrieval of CCC, the empirical transfer function based on the S2TCI provided the best performance when assessed against the in-situ data, demonstrating a moderate but significant correlation $(r=0.56$, $p<0.01)$ and $\mathrm{RMSE}_{\mathrm{CV}}$ of $0.09 \mathrm{~g} \mathrm{~m}^{-2}\left(\mathrm{NRMSE}_{\mathrm{CV}}=20.93 \%\right)$ (Fig. 4). The associated $20 \mathrm{~m}$ CCC reference map demonstrated good spatial consistency with observed patterns of vegetation cover over the Valencia Anchor Station (Fig. 5). The raw ANN retrievals were characterized by a weaker correlation $(r=0.48$, $p<0.01)$ and substantially lower retrieval accuracy $(\mathrm{RMSE}=$ $0.14 \mathrm{~g} \mathrm{~m}^{-2}, \mathrm{NRMSE}=32.56 \%$ ), although retrieval accuracy post bias-correction was comparable $\left(\mathrm{RMSE}_{\mathrm{CV}}=0.09 \mathrm{~g} \mathrm{~m}^{-2}\right.$, NRMSE $\left._{C V}=20.93 \%\right)($ Fig. 4$)$.
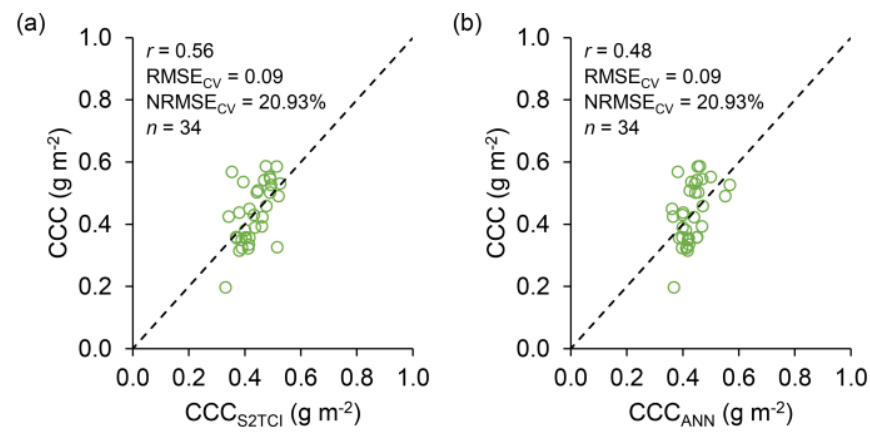

Fig. 4. Comparison between in-situ and retrieved CCC using the empirical transfer function (a) and bias-corrected ANN (b). The dashed line represents a $1: 1$ relationship.

Our results compare favorably to those of [40], who applied similar techniques to $6.5 \mathrm{~m}$ RapidEye data, achieving an RMSE of 0.39 to $0.43 \mathrm{~g} \mathrm{~m}^{-2}$. Given the retrieval accuracies obtained in our study, we suggest that the moderate correlations observed are primarily the result of a limited range of in-situ CCC values experienced over the Valencia Anchor Station (0.20 to $0.59 \mathrm{~g}$ $\mathrm{m}^{-2}$ ) (Table II and Fig. 6). This is primarily driven by the low range in LAI values over the site, and is particularly apparent 
when compared to previous validation efforts, which have incorporated in-situ CCC values of up to $3.5 \mathrm{~g} \mathrm{~m}^{-2}$ [27].

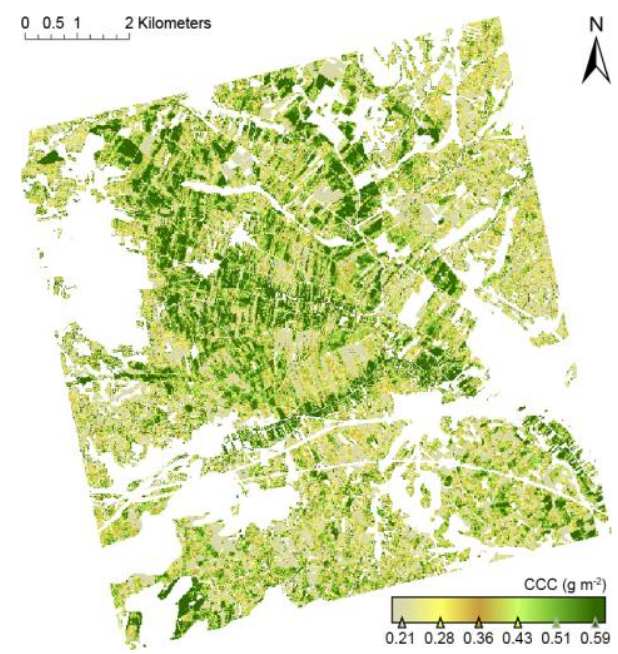

Fig. 5. $20 \mathrm{~m} \mathrm{CCC}$ reference map derived using the empirical transfer function (areas not covered by considered land cover types masked).

TABLE II

DESCRIPTIVE STATISTICS ASSOCIATED WITH IN-SITU LAI, LCC AND CCC VALUES OBSERVED AT THE VALENCIA ANCHOR STATION

\begin{tabular}{lccc}
\hline \hline Statistic & LAI & LCC $\left(\mathrm{g} \mathrm{m}^{-2}\right)$ & CCC $\left(\mathrm{g} \mathrm{m}^{-2}\right)$ \\
\hline Minimum & 0.66 & 0.21 & 0.20 \\
Maximum & 2.26 & 0.44 & 0.59 \\
Mean & 1.37 & 0.32 & 0.43 \\
Standard deviation & 0.33 & 0.05 & 0.10 \\
\hline \hline
\end{tabular}

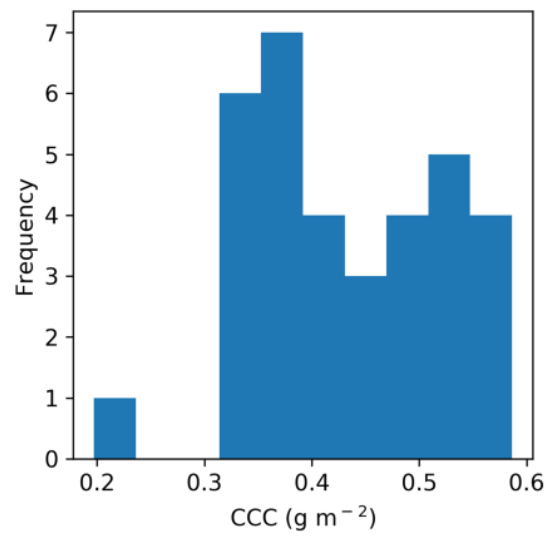

Fig. 6. Frequency distribution of in-situ CCC values observed at the Valencia Anchor Station.

\section{B. Performance of the OTCI}

Good spatial consistency was observed between the $300 \mathrm{~m}$ CCC reference map and OTCI when the mean value downsampling aggregation strategy was adopted (Fig. 7). All major spatial structures apparent in the $300 \mathrm{~m} \mathrm{CCC}$ reference map were resolved by the OTCI, reflected by the strong and significant correlation observed between the two datasets $(r=$
$0.77, p<0.01$ ) (Fig. 8). The empirical relationship established between the OTCI and CCC was

$y=0.1452 x+0.1191$

where $y$ is CCC in $\mathrm{g} \mathrm{m}^{-2}$ and $x$ is the OTCI, yielding an $\mathrm{RMSE}_{\mathrm{CV}}$ of $0.02 \mathrm{~g} \mathrm{~m}^{-2}\left(\mathrm{NRMSE}_{\mathrm{CV}}=5.00 \%\right)$.

It is important to note that these results are with respect to the $300 \mathrm{~m}$ CCC reference map derived from MSI data (see Section II $\mathrm{B}$ and $\mathrm{C}$ ), which also has associated errors. In the worst case scenario, the errors in the $300 \mathrm{~m} \mathrm{CCC}$ reference map could be assumed equal to those in the $20 \mathrm{~m} \mathrm{CCC} \mathrm{reference} \mathrm{map.} \mathrm{In} \mathrm{this}$ case, and assuming no correlation between errors, a combined RMSE could be derived by adding the individual RMSE values in quadrature (yielding an $\mathrm{RMSE}_{\mathrm{CV}}$ of $0.09 \mathrm{~g} \mathrm{~m}^{-2}$ and NRMSE $_{C V}$ of $21.52 \%$ ). In reality, however, the random component of the errors in the $20 \mathrm{~m} \mathrm{CCC}$ reference map will be reduced by mean value downsampling as a function of the number of pixels used in aggregation. Therefore, when applied over similar vineyard dominated Mediterranean environments, this combined value may underestimate the accuracy of CCC retrievals derived using the presented empirical relationship.
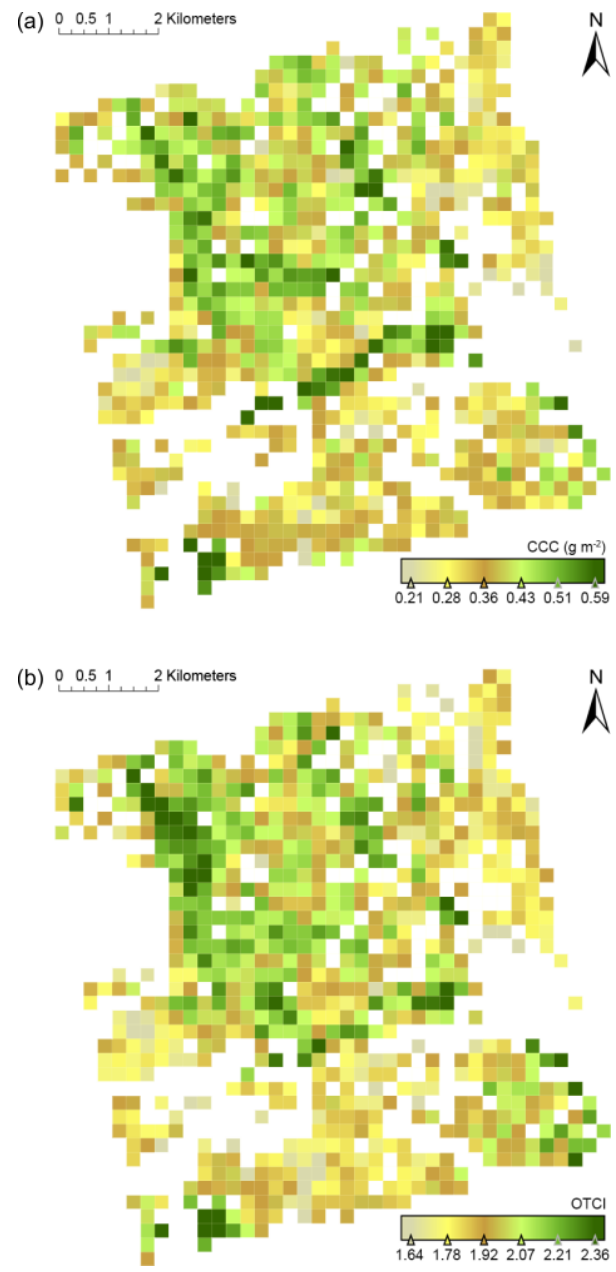

Fig. 7. $300 \mathrm{~m} \mathrm{CCC}$ reference map, aggregated using mean value downsampling (a) and OTCI (b) (areas not covered by considered land cover types masked). 
When the weighted mean value downsampling strategy was adopted, a substantially weaker correlation between the OTCI and $300 \mathrm{~m} \mathrm{CCC}$ reference map was observed $(r=0.52, p<$ 0.01 ). This result indicates that a) the influence of OLCI's PSF may be less than that of the PSF assumed in this study, and that b) such a simple model of the PSF may be unable to accurately represent the observational characteristics of the instrument, which are also affected by factors such as viewing geometry. As such, if the PSF is to be accounted for in aggregation, further work is required to better describe these effects.
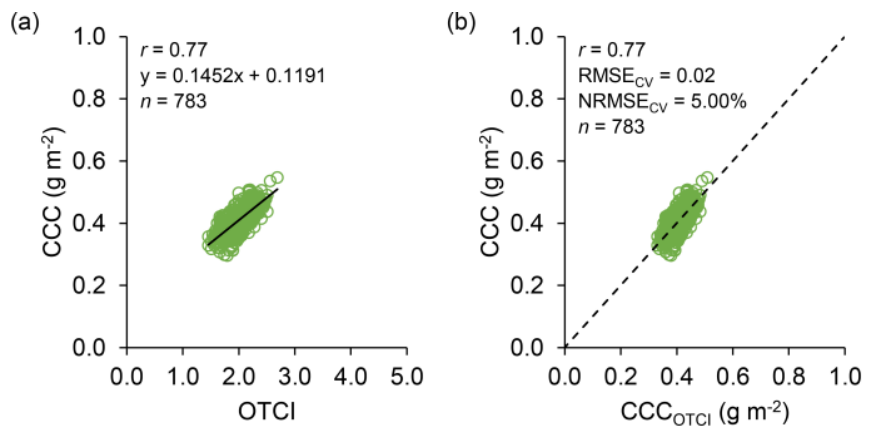

Fig. 8. Comparison between upscaled CCC and the OTCI (a) and OTCIbased CCC retrievals (b). The solid line (a) represents the established empirical relationship (7) whilst the dashed line (b) represents a 1:1 relationship.

\section{Synergetic potential of the Sentinel-2 missions for validation of moderate spatial resolution CCC products}

Row-structured canopies such as the vineyards and almond/olive groves of the Valencia Anchor Station represent a challenging environment for biophysical variable retrieval, as a result of high foliage clumping, the substantial influence of the soil background, and strong bidirectional reflectance distribution function (BRDF) effects. Nevertheless, we established and successfully applied a framework for the direct validation of moderate spatial resolution CCC products making synergetic use of MSI data. The results of this study indicate that MSI data are well suited to the retrieval of CCC, and thus provide valuable information that can be used in synergy with OLCI data for the purposes of L2 land product validation. Overall, good agreement between the OTCI and upscaled CCC was observed, providing increased confidence to users of the product over vineyard dominated Mediterranean environments. Having tested the framework over the Valencia Anchor Station, there is now a need for future work to apply it over additional sites, covering a wide range of globally representative vegetation types.

When compared to infrequent airborne hyperspectral acquisition, the Sentinel-2 missions represent a major advance towards the routine validation of moderate spatial resolution CCC products such as the OTCI. This is an important development that will enable progress towards the second stage of the CEOS WGCV LPV hierarchy, which states that product accuracy should be estimated over a significant set of locations and time periods [18]. In addition to their utility for upscaling in-situ measurements using the 'two-stage' or 'bottom-up' approach, the red-edge bands provided by MSI open up opportunities for deriving spectral vegetation indices similar to the OTCI at a higher spatial resolution than previously possible.
With appropriate consideration of differences in spectral response [41] and other observational characteristics such as viewing and illumination geometry, this capability could be further exploited for indirect validation (i.e. inter-mission comparison) on an operational basis.

\section{CONCLUSIONS}

In this paper, we explored the synergetic use of MSI data for validation of the OTCI over a large agricultural site in the Valencian Community, Spain. We established and successfully applied a framework for the direct validation of moderate spatial resolution CCC products making synergetic use of MSI data. Good agreement between the OTCI and upscaled CCC was observed, providing increased confidence to users of the product over vineyard dominated Mediterranean environments. Importantly, the retrieval accuracies achieved by applying empirical and machine learning techniques to MSI data highlight the valuable information it can provide when used in synergy with OLCI data for L2 land product validation. The Sentinel-2 missions are thus a key facilitator of operational validation activities, and should enable moderate spatial resolution CCC products such as the OTCI to progress towards the second stage of the CEOS WGCV LPV hierarchy. To achieve this objective, future work is required to apply the proposed framework over additional sites, covering a wide range of globally representative vegetation types.

\section{ACKNOWLEDGMENT}

The authors thank the European Space Agency and European Commission for making the Sentinel products and tools freely available through the Copernicus programme, in addition to Jaan Praks for providing a copy of rowMCRM. The authors are also grateful to Francesco D'Adamo, Andrew MacLachlan, Harry Morris, Erika Albero, Pilar Campíns-Falcó, Domingo Catalan, Amparo Coll Pajaron, María Amparo Gilabert, Beatriz Martínez, Sergio Sánchez-Ruiz, Aida Vicente, Inmaculada Bautista, Cristina Lull, Jennifer Adams, Nadine Gobron, Christian Lanconelli, Olivier Morgan and Domingo Iglesias for their assistance in campaign planning and execution.

\section{REFERENCES}

[1] D. N. H. Horler, M. Dockray, and J. Barber, "The red edge of plant leaf reflectance," Int. J. Remote Sens., vol. 4, no. 2, pp. 273-288, Jan. 1983.

[2] A. A. Gitelson, M. N. Merzlyak, and H. K. Lichtenthaler, "Detection of Red Edge Position and Chlorophyll Content by Reflectance Measurements Near 700 nm," J. Plant Physiol., vol. 148, no. 3-4, pp. 501-508, 1996.

[3] J. G. P. W. Clevers and A. A. Gitelson, "Remote estimation of crop and grass chlorophyll and nitrogen content using red-edge bands on Sentinel-2 and -3," Int. J. Appl. Earth Obs. Geoinf., vol. 23, no. 1, pp. 344-351, Aug. 2013.

[4] T. P. Dawson and P. J. Curran, "Technical note A new technique for interpolating the reflectance red edge position," Int. J. Remote Sens., vol. 19, no. 11, pp. 2133-2139, Jan. 1998.

[5] R. A. Jago, M. E. . Cutler, and P. J. Curran, "Estimating Canopy Chlorophyll Concentration from Field and Airborne Spectra," Remote Sens. Environ., vol. 68, no. 3, pp. 217-224, Jun. 1999.

[6] J. Dash and P. J. Curran, "The MERIS terrestrial chlorophyll index," Int. J. Remote Sens., vol. 25, no. 23, pp. 5403-5413, Dec. 2004.

[7] J. Dash, C. Jeganathan, and P. M. Atkinson, "The use of MERIS 
Terrestrial Chlorophyll Index to study spatio-temporal variation in vegetation phenology over India," Remote Sens. Environ., vol. 114, no. 7 , pp. $1388-1402$, Jul. 2010.

[8] C. Jeganathan, J. Dash, and P. M. Atkinson, "Mapping the phenology of natural vegetation in India using a remote sensingderived chlorophyll index," Int. J. Remote Sens., vol. 31, no. 22, pp. 5777-5796, Dec. 2010.

[9] D. S. Boyd, S. Almond, J. Dash, P. J. Curran, and R. A. Hill, "Phenology of vegetation in Southern England from Envisat MERIS terrestrial chlorophyll index (MTCI) data," Int. J. Remote Sens., vol. 32, no. 23, pp. 8421-8447, Dec. 2011.

[10] D. S. Boyd, S. Almond, J. Dash, and P. J. Curran, "Investigating the Factors Affecting the Relationship Between the ENVISAT MERIS Terrestrial Chlorophyll Index (MTCI) and Chlorophyll Content: Preliminary Findings," in Proceedings of the 2007 RSPSoc Annual Conference, 2007.

[11] G. M. Foody and J. Dash, "Estimating the relative abundance of C3and C4grasses in the Great Plains from multi-temporal MTCI data: Issues of compositing period and spatial generalizability," Int. J. Remote Sens., vol. 31, no. 2, pp. 351-362, 2010.

[12] P. J. Curran, J. Dash, and G. M. Llewellyn, "Indian Ocean tsunami: The use of MERIS (MTCI) data to infer salt stress in coastal vegetation," Int. J. Remote Sens., vol. 28, no. 3-4, pp. 729-735, 2007.

[13] A. Harris and J. Dash, "The potential of the MERIS Terrestrial Chlorophyll Index for carbon flux estimation," Remote Sens. Environ., vol. 114, no. 8, pp. 1856-1862, Aug. 2010.

[14] D. S. Boyd, S. Almond, J. Dash, P. J. Curran, R. A. Hill, and G. M. Foody, "Evaluation of Envisat MERIS Terrestrial Chlorophyll Index-Based Models for the Estimation of Terrestrial Gross Primary Productivity," IEEE Geosci. Remote Sens. Lett., vol. 9, no. 3, pp. 457-461, May 2012.

[15] B. O. Ogutu, J. Dash, and T. P. Dawson, "Developing a diagnostic model for estimating terrestrial vegetation gross primary productivity using the photosynthetic quantum yield and Earth Observation data," Glob. Chang. Biol., vol. 19, no. 9, pp. 28782892, Sep. 2013.

[16] S. Zhang and L. Liu, "The potential of the MERIS Terrestrial Chlorophyll Index for crop yield prediction," Remote Sens. Lett., vol. 5, no. 8, pp. 733-742, Aug. 2014

[17] J. T. Morisette et al., "Validation of global moderate-resolution LAI products: a framework proposed within the CEOS land product validation subgroup," IEEE Trans. Geosci. Remote Sens., vol. 44, no. 7, pp. 1804-1817, Jul. 2006.

[18] R. Fernandes et al., "Global Leaf Area Index Product Validation Good Practices," in Best Practice for Satellite-Derived Land Product Validation, 2.0., R. Fernandes, S. Plummer, and J. Nightingale, Eds. Land Product Validation Subgroup (Committee on Earth Observation Satellites Working Group on Calibration and Validation), 2014.

[19] E. Lopez-Baeza et al., "SMOS land validation activities at the Valencia Anchor Station," in Proceedings of the XV Congreso de la Asociación Española de Teledetección, 2013.

[20] F. Gascon et al., "Copernicus Sentinel-2A Calibration and Products Validation Status," Remote Sens., vol. 9, no. 6, p. 584, Jun. 2017.

[21] B. Martínez, F. J. García-Haro, and F. Camacho-de Coca, "Derivation of high-resolution leaf area index maps in support of validation activities: Application to the cropland Barrax site," Agric. For. Meteorol., vol. 149, no. 1, pp. 130-145, Jan. 2009.

[22] M. Weiss and F. Baret, CAN-EYE V6.4.91 User Manual. Avignon, France: Institut National de la Recherche Agronomique, 2017.

[23] J. Miller, "A formula for average foliage density," Aust. J. Bot., vol. 15, no. 1, pp. 141-144, Apr. 1967.

[24] A. R. G. Lang and X. Yueqin, "Estimation of leaf area index from transmission of direct sunlight in discontinuous canopies," Agric. For. Meteorol., vol. 37, no. 3, pp. 229-243, Aug. 1986.

[25] C. Parry, J. M. Blonquist, and B. Bugbee, "In situ measurement of leaf chlorophyll concentration: analysis of the optical/absolute relationship," Plant. Cell Environ., vol. 37, no. 11, pp. 2508-2520, Nov. 2014

[26] A. R. Wellburn, "The Spectral Determination of Chlorophylls a and b, as well as Total Carotenoids, Using Various Solvents with Spectrophotometers of Different Resolution," J. Plant Physiol., vol. 144, no. 3, pp. 307-313, Sep. 1994.

[27] F. Vuolo, J. Dash, P. J. Curran, D. Lajas, and E. Kwiatkowska,
"Methodologies and Uncertainties in the Use of the Terrestrial Chlorophyll Index for the Sentinel-3 Mission," Remote Sens., vol. 4, no. 12, pp. 1112-1133, Apr. 2012.

[28] P. J. Zarco-Tejada et al., "Assessing vineyard condition with hyperspectral indices: Leaf and canopy reflectance simulation in a row-structured discontinuous canopy," Remote Sens. Environ., vol. 99, no. 3, pp. 271-287, Nov. 2005.

[29] F. Meggio, P. J. Zarco-Tejada, J. R. Miller, P. Martín, M. R. González, and A. Berjón, "Row orientation and viewing geometry effects on row-structured vine crops for chlorophyll content estimation," Can. J. Remote Sens., vol. 34, no. 3, pp. 220-234, 2008.

[30] W. Verhoef, "Light scattering by leaf layers with application to canopy reflectance modeling: The SAIL model," Remote Sens. Environ., vol. 16, no. 2, pp. 125-141, Oct. 1984

[31] W. Verhoef, L. Jia, Q. Xiao, and Z. Su, "Unified Optical-Thermal Four-Stream Radiative Transfer Theory for Homogeneous Vegetation Canopies," IEEE Trans. Geosci. Remote Sens., vol. 45, no. 6, pp. 1808-1822, Jun. 2007.

[32] S. Jacquemoud and F. Baret, "PROSPECT: A model of leaf optical properties spectra," Remote Sens. Environ., vol. 34, no. 2, pp. 7591, Nov. 1990.

[33] J.-B. Feret et al., "PROSPECT-4 and 5: Advances in the leaf optical properties model separating photosynthetic pigments," Remote Sens. Environ., vol. 112, no. 6, pp. 3030-3043, Jun. 2008.

[34] A. M. Baldridge, S. J. Hook, C. I. Grove, and G. Rivera, "The ASTER spectral library version 2.0," Remote Sens. Environ., vol. 113, no. 4, pp. 711-715, Apr. 2009.

[35] ESA, "Sentinel-2 Spectral Response Functions (S2-SRF)," 2017. [Online]. Available: https://earth.esa.int/documents/247904/685211/Sentinel2+MSI+Spectral+Responses/. [Accessed: 16-May-2017].

[36] A. Verger, F. Baret, and F. Camacho, "Optimal modalities for radiative transfer-neural network estimation of canopy biophysical characteristics: Evaluation over an agricultural area with CHRIS/PROBA observations," Remote Sens. Environ., vol. 115, no. 2, pp. 415-426, Feb. 2011.

[37] F. Baret et al., VALERI : a network of sites and a methodology for the validation of medium spatial resolution land satellite products. Avignon, France: Institut National de la Recherche Agronomique, 2005.

[38] W. J. Frampton, J. Dash, G. Watmough, and E. J. Milton, "Evaluating the capabilities of Sentinel-2 for quantitative estimation of biophysical variables in vegetation," ISPRS J. Photogramm. Remote Sens., vol. 82, pp. 83-92, Aug. 2013.

[39] J. Amorós-López et al., "Multitemporal fusion of Landsat/TM and ENVISAT/MERIS for crop monitoring," Int. J. Appl. Earth Obs. Geoinf., vol. 23, no. 1, pp. 132-141, Aug. 2013.

[40] F. Vuolo, C. Atzberger, K. Richter, and J. Dash, "Retrieval of Biophysical Vegetation Products From Rapideye Imagery," in Proceedings of the ISPRS TC VII Symposium, 2010, pp. 281-286.

[41] G. Chander et al., "Applications of Spectral Band Adjustment Factors (SBAF) for Cross-Calibration," IEEE Trans. Geosci. Remote Sens., vol. 51, no. 3, pp. 1267-1281, Mar. 2013.

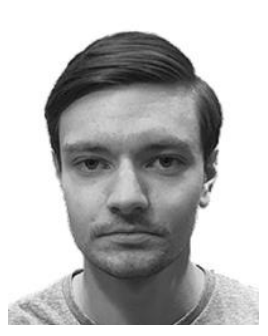

Luke A. Brown was born in Ascot, United Kingdom in 1993. He received the B.Sc. degree in geography from the University of Southampton, United Kingdom in 2014, from where he then received the M.Sc. degree in applied geographic information systems and remote sensing in 2015.

He is currently a Senior Research Assistant with the School of Geography and Environmental Science, University of Southampton, where he previously worked as a Research Technician from 2017 to 2018, and where he is also pursuing the Ph.D. degree in remote sensing. His research interests are in the retrieval of vegetation biophysical and biochemical variables from optical remote sensing data, and in their validation using in-situ measurement techniques. 


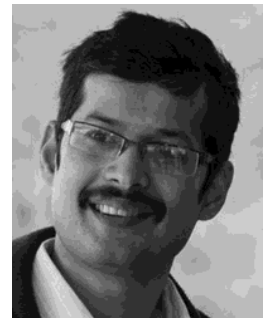

Jadunandan Dash received the M.Tech. degree in civil engineering from the Indian Institute of Technology, Kanpur, India in 2002, and the Ph.D. degree in remote sensing from the University of Southampton, United Kingdom in 2005.

He is currently a Professor in Remote Sensing with the School of Geography and Environmental Science, University of Southampton, where he has been a staff member since 2006. He has a strong research background in pure and applied remote sensing, particularly in algorithm development, validation of vegetation biophysical products from earth observation data, and spatio-temporal analysis of earth observation data to understand the state of the world's ecosystems and the impacts of climate change.

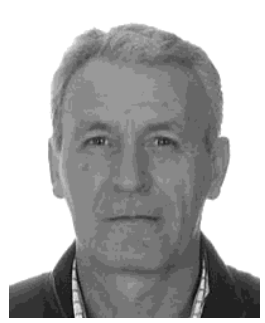

Antonio L. Lidón was born in Murcia, Spain in 1963. $\mathrm{He}$ graduated in agricultural engineering from the Technical University of Valencia in 1989, from where he then received the Ph.D. degree in 1994.

From 1994 to 1997, he was a Research Assistant with the Valencian Institute of Agricultural Research. Since 2002, he has been an Associate Professor with the Department of Chemistry, School of Agricultural Engineering and Environment, Technical University of Valencia, where he is a member of the Research Institute for Water and Environmental Engineering. During this period, he has participated in different research projects and engineering studies related to environmental pollution in agricultural systems, the use efficiency of nitrogen in horticultural crops, plant responses to abiotic stress in natural habitats, and the hydrological characterization of forest structures at plot scale for adaptive management. $\mathrm{He}$ is currently a member of the Horticultural Science Spanish Society and the Spanish Society of Soil Science.

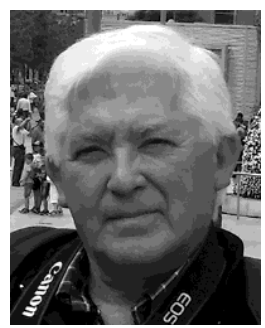

Ernesto Lopez-Baeza received the Ph.D. degree in physics from the University of Valencia, Spain, in 1986.

$\mathrm{He}$ is an Associate Professor in Applied Physics with the Department of Earth Physics and Thermodynamics, University of Valencia since 1987, and Director of the Climatology from Satellites Group since the year 2000. He is responsible for the Valencia Anchor Station surface validation site. His research interests have included ground validation activities in the framework of EUMETSAT Geostationary Earth Radiation Budget (GERB), NASA Cloud and the Earth's Radiant Energy System (CERES), and ESA/EUMETSAT EPS/MetOp. He is currently involved in similar scientific activities for earth observation missions including Soil Moisture Active Passive (SMAP) from NASA, Soil Moisture and Ocean Salinity (SMOS) from ESA, and OLCI onboard Copernicus Sentinel-3, and is preparing for ESA/JAXA Earth Clouds, Aerosols and Radiation Explorer (EarthCARE).

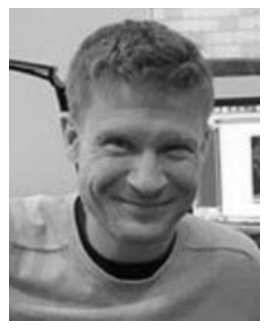

Steffen Dransfeld was born in Jever, Germany in 1974. He received the M.Eng degree in electrical and electronic engineering from the University of Surrey, Guildford, United Kingdom in 1998, and the Ph.D. degree in satellite oceanography from the University of Southampton, United Kingdom in 2003.

From 2003 to 2005 he was a Marie Curie Postdoctoral Research Fellow with CLS, Toulouse, France, studying feature tracking from Advanced Very High Resolution Radiometer (AVHRR) imagery to measure ocean currents. From 2005 to 2007 he was with the Institute of Oceanography, University of Hamburg, Germany, where he managed the German SMOS Project Office, developing calibration and validation studies. Since 2007, he has been with the European Space Research Institute, European Space Agency,
Frascati, Italy, working initially as a Research Fellow, and subsequently, a Ground Segment Systems Engineer. His most recent and current area of responsibility is the management of data quality activities related to the OLCI and Sea and Land Surface Temperature Radiometer (SLSTR) instruments onboard the Sentinel-3 mission. 